\title{
Performance of Ventilators Compatible With Magnetic Resonance Imaging: A Bench Study
}

\author{
Yusuke Chikata PhD, Nao Okuda MD, Masayo Izawa MD, \\ Mutsuo Onodera MD, and Masaji Nishimura MD PhD
}

\begin{abstract}
BACKGROUND: Magnetic resonance imaging (MRI) is indispensable for diagnosing brain and spinal cord abnormalities. Magnetic components cannot be used during MRI procedures; therefore, patient support equipment must use MRI-compatible materials. However, little is known of the performance of MRI-compatible ventilators. METHODS: At commonly used settings, we tested the delivered tidal volume $\left(\mathrm{V}_{\mathrm{T}}\right), \mathrm{F}_{\mathrm{IO}}$, PEEP, and operation of the high-inspiratory-pressure-relief valves of 4 portable MRI-compatible ventilators (Pneupac VR1, ParaPAC 200DMRI, CAREvent MRI, iVent201) and one ICU ventilator (Servo-i). Each ventilator was set in volume control/ continuous mandatory ventilation mode. Breathing frequency and $V_{T}$ were tested at $10 \mathrm{breaths} / \mathrm{min}$ and 300, 500, and $700 \mathrm{~mL}$, respectively. The Pneupac VR1 has fixed $V_{T}$ and frequency combinations, so it was tested at $V_{T}=300 \mathrm{~mL}$ and 20 breaths $/ \mathrm{min}, V_{T}=500 \mathrm{~mL}$ and 12 breaths $/ \mathrm{min}$, and $\mathrm{V}_{\mathrm{T}}=800 \mathrm{~mL}$ and 10 breaths/min. $\mathrm{F}_{\mathrm{IO}_{2}}$ was 0.6 and 1.0 . At the air-mix setting, $\mathrm{F}_{\mathrm{IO}_{2}}$ was fixed at 0.5 with the Pneupac VR1, 0.45 with the ParaPAC 200DMRI, and 0.6 with the CAREvent MRI. PEEP

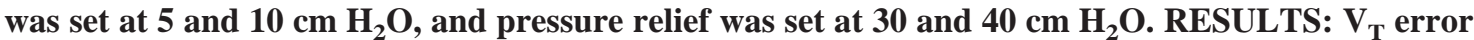
varied widely among ventilators $(-28.1$ to $25.5 \%)$. As $V_{T}$ increased, error decreased with the Pneupac VR1, ParaPAC 200DMRI, and CAREvent MRI $(P<.05) . \mathrm{F}_{\mathrm{IO}_{2}}$ error ranged from -13.3 to $25.3 \%$ at 0.6 (or air mix). PEEP error varied among ventilators $(-29.2$ to $42.5 \%$ ). Only the Servo-i maintained $\mathrm{V}_{\mathrm{T}}, \mathrm{F}_{\mathrm{IO}}$, and PEEP at set levels. The pressure-relief valves worked in all ventilators. CONCLUSIONS: None of the MRI-compatible ventilators maintained $\mathrm{V}_{\mathrm{T}}, \mathrm{F}_{\mathrm{IO}}$, and PEEP at set levels. Vital signs of patients with unstable respiratory mechanics should be monitored during transport and MRI. Key words: magnetic resonance imaging; MRI; MRI-compatible ventilator. [Respir Care 2015;60(3):341-346. (C) 2015 Daedalus Enterprises]
\end{abstract}

\section{Introduction}

Magnetic resonance imaging (MRI) has become essential for diagnosing abnormalities in the brain, spinal cord,

Dr Chikata is affiliated with the Medical Equipment Center, Tokushima University Hospital, Tokushima, Japan. Drs Okuda, Izawa, Onodera, and Nishimura are affiliated with Emergency and Critical Care Medicine, Tokushima University Graduate School, Tokushima, Japan.

The authors have disclosed no conflicts of interest.

Correspondence: Masaji Nishimura MD PhD, Emergency and Critical Care Medicine, Tokushima University Graduate School, 3-18-15 Kuramoto, Tokushima 770-8503, Japan. E-mail: nmasaji@tokushima-u.ac.jp.

DOI: $10.4187 /$ respcare. 03528 spine, and major joints that are undetectable using conventional imaging techniques. Many patients require ventilatory support during transport and the MRI procedure. In MRI suites, conventional ventilators with ferromagnetic components have a number of issues, including risk of projectile events, degradation of image quality, and compromised ventilator performance. ${ }^{1,2}$ Portable ventilators do not perform as well as ICU ventilators ${ }^{3}$; in addition, MRIcompatible ventilators have their ferromagnetic components replaced with non-ferromagnetic components made of aluminum alloy and other materials. Although regular delivery of accurate tidal volume $\left(\mathrm{V}_{\mathrm{T}}\right)$, PEEP, and $\mathrm{F}_{\mathrm{IO}_{2}}$ is crucial for critically ill patients, we found few studies detailing the performance of MRI-compatible portable ventilators. Consequently, in a non-MRI environment, we carried out this bench study to evaluate the performance of MRI-compatible portable ventilators. 


\section{Methods}

\section{Ventilators Tested}

Along with one ICU ventilator (Servo-i, Maquet, Wayne, New Jersey) used as a control, we tested 4 portable MRIcompatible ventilators: Pneupac VR1 (Smiths Medical, Watford, United Kingdom), ParaPAC 200DMRI (Smiths Medical), CAREvent MRI (O-Two Medical Technologies, Mississauga, Ontario, Canada), and iVent201 (GE Healthcare, Madison, Wisconsin) (Table 1). We checked the accuracy of delivered $\mathrm{V}_{\mathrm{T}}, \mathrm{F}_{\mathrm{IO}_{2}}$, PEEP, and alarm function of high-airway-pressure relief.

\section{$\mathrm{V}_{\mathrm{T}}$ and Breathing Frequency}

All ventilators were tested in volume control/continuous mandatory ventilation mode. The Pneupac VR1 offers only fixed combinations of $\mathrm{V}_{\mathrm{T}}$ and breathing frequency: it was tested at $300 \mathrm{~mL}$ and 20 breaths $/ \mathrm{min}, 500 \mathrm{~mL}$ and 12 breaths/min, and $800 \mathrm{~mL}$ and 10 breaths/min. With the other ventilators, breathing frequency was set at 10 breaths/ min, and $\mathrm{V}_{\mathrm{T}}$ was set at 300,500 , and $700 \mathrm{~mL}$.

$\mathbf{F}_{\mathrm{IO}_{2}}$

Two levels of $\mathrm{F}_{\mathrm{IO}_{2}}$ (1.0 and air mix) were available with the Pneupac VR1 (air mix, $\mathrm{F}_{\mathrm{IO}_{2}}=0.5$ ), ParaPAC 200DMRI (air mix, $\mathrm{F}_{\mathrm{IO}_{2}}=0.45$ ), and CAREvent MRI (air mix, $\mathrm{F}_{\mathrm{IO}_{2}}=0.6$ ). On the iVent 201 and Servo-i, $\mathrm{F}_{\mathrm{IO}_{2}}$ was set at 1.0 and 0.6.

\section{PEEP}

PEEP on the CAREvent MRI, iVent201, and Servo-i was set at 5 and $10 \mathrm{~cm} \mathrm{H}_{2} \mathrm{O}$. To apply PEEP, the Pneupac VR1 and ParaPAC 200DMRI required a PEEP valve with spring, a ferromagnetic component that would be unsuitable for use in an MRI suite.

\section{Alarm Function of High-Pressure-Relief Valves}

The alarm function of high-pressure relief was tested at 30 and $40 \mathrm{~cm} \mathrm{H}_{2} \mathrm{O}$ with $\mathrm{V}_{\mathrm{T}}$ set at $1,000 \mathrm{~mL}$ and compliance of $0.02 \mathrm{~L} / \mathrm{cm} \mathrm{H}_{2} \mathrm{O}$ (peak inspiratory pressure was $>50 \mathrm{~cm} \mathrm{H}_{2} \mathrm{O}$ ). With the Pneupac VR1, the available fixed value was $40 \mathrm{~cm} \mathrm{H}_{2} \mathrm{O}$.

\section{Compliance and Resistance}

The compliance of the TTL test lung (model 1601, Michigan Instruments, Grand Rapids, Michigan) was adjusted to 0.05 and $0.02 \mathrm{~L} / \mathrm{cm} \mathrm{H}_{2} \mathrm{O}$ with a resistance of 5 and $20 \mathrm{~cm} \mathrm{H}_{2} \mathrm{O} / \mathrm{L} / \mathrm{s}$, respectively (see Table 1).

\section{QUICK LOOK}

\section{Current knowledge}

Magnetic resonance imaging (MRI) has become essential for diagnosing abnormalities in the brain, spinal cord, and spine. Many patients require ventilatory support during transport to and during magnetic resonance imaging. In MRI suites, conventional ventilators can contribute to risk of projectile events, degradation of image quality, and compromised ventilator performance.

\section{What this paper contributes to our knowledge}

None of the MRI-compatible ventilators maintained $\mathrm{V}_{\mathrm{T}}$, $\mathrm{F}_{\mathrm{IO}_{2}}$ and PEEP at set levels. Additional monitoring of vital signs in patients with unstable respiratory mechanics should be performed during transport and MRI.

\section{Experimental Setup}

Each ventilator was connected to a TTL test lung via the supplied or standard limb tubing. With the iVent201 and Servo-i, compression volume was corrected with self-test procedures. An oxygen analyzer ( $\mathrm{S} / 5$ compact monitor, GE Healthcare), pressure transducer (TM6600, San-You Technology, Saitama, Japan), and pneumotachometer (4700 series, 0-160 L/min, Hans Rudolph, Shawnee, Kansas) were placed between the Y-piece of the ventilator limb and the TTL test lung. The pneumotachometer was connected to a differential pressure transducer (TP-602T, $\pm 5 \mathrm{~cm} \mathrm{H}_{2} \mathrm{O}$, Nihon Kohden, Tokyo, Japan) to measure flow (Fig. 1). The oxygen analyzer was self-calibrated automatically at an $\mathrm{F}_{\mathrm{IO}_{2}}$ of 0.21 , and the pneumotachometer was calibrated using a 1.0-L supersyringe. We monitored flow, $\mathrm{F}_{\mathrm{IO}_{2}}$, and airway pressure for $15 \mathrm{~min}$, and after confirming the constancy of the values, we recorded them for $1 \mathrm{~min}$. Each signal was processed through an analogto-digital converter and saved on a computer at $50 \mathrm{~Hz} /$ channel using data acquisition software (WinDaq, DATAQ Instruments, Akron, Ohio). Delivered $\mathrm{V}_{\mathrm{T}}$ was calculated later by digital integration of expiratory flow signals.

\section{Analysis and Statistics}

Values were shown as percent error:

\%error $=100 \times($ measured value - set value $) /$ set value

Statistical analysis was performed using repeated-measures analysis of variance. All statistical tests were 2-sided. Statistical analysis was performed using commercial soft- 
Table 1. Tested Ventilators and Experimental Settings

\begin{tabular}{|c|c|c|c|c|c|c|c|}
\hline Model & Manufacturer & $\mathrm{V}_{\mathrm{T}}(\mathrm{mL})$ & $\mathrm{F}_{\mathrm{IO}_{2}}$ & $\begin{array}{l}\text { Compliance } \\
\left(\mathrm{L} / \mathrm{cm} \mathrm{H}_{2} \mathrm{O}\right)\end{array}$ & $\begin{array}{c}\text { Resistance } \\
\left.\text { (cm H} \mathrm{H}_{2} \mathrm{O} / \mathrm{L} / \mathrm{s}\right)\end{array}$ & $\begin{array}{c}\text { PEEP } \\
\left(\mathrm{cm} \mathrm{H}_{2} \mathrm{O}\right)\end{array}$ & $\begin{array}{c}\text { Safety Valve } \\
\text { of PIP } \\
\left(\mathrm{cm} \mathrm{H}_{2} \mathrm{O}\right)\end{array}$ \\
\hline Pneupac VR1 & Smiths Medical & $300(20), 500(12), 800(10)^{*}$ & $1.0,0.5$ & $0.05,0.02$ & 5,20 & Non & 40 \\
\hline ParaPAC 200DMRI & Smiths Medical & $300,500,700$ & $1.0,0.45$ & $0.05,0.02$ & 5,20 & Non & 30,40 \\
\hline CAREvent MRI & O-Two Medical Technologies & $300,500,700$ & $1.0,0.6$ & $0.05,0.02$ & 5,20 & 5,10 & 30,40 \\
\hline iVent201 & GE Healthcare & $300,500,700$ & $1.0,0.6$ & $0.05,0.02$ & 5,20 & 5,10 & 30,40 \\
\hline Servo-i & Maquet & $300,500,700$ & $1,0,0.6$ & $0.05,0.02$ & 5,20 & 5,10 & 30,40 \\
\hline
\end{tabular}

* Values in parentheses indicate breathing frequency (breaths/min).

PIP $=$ peak inspiratory pressure

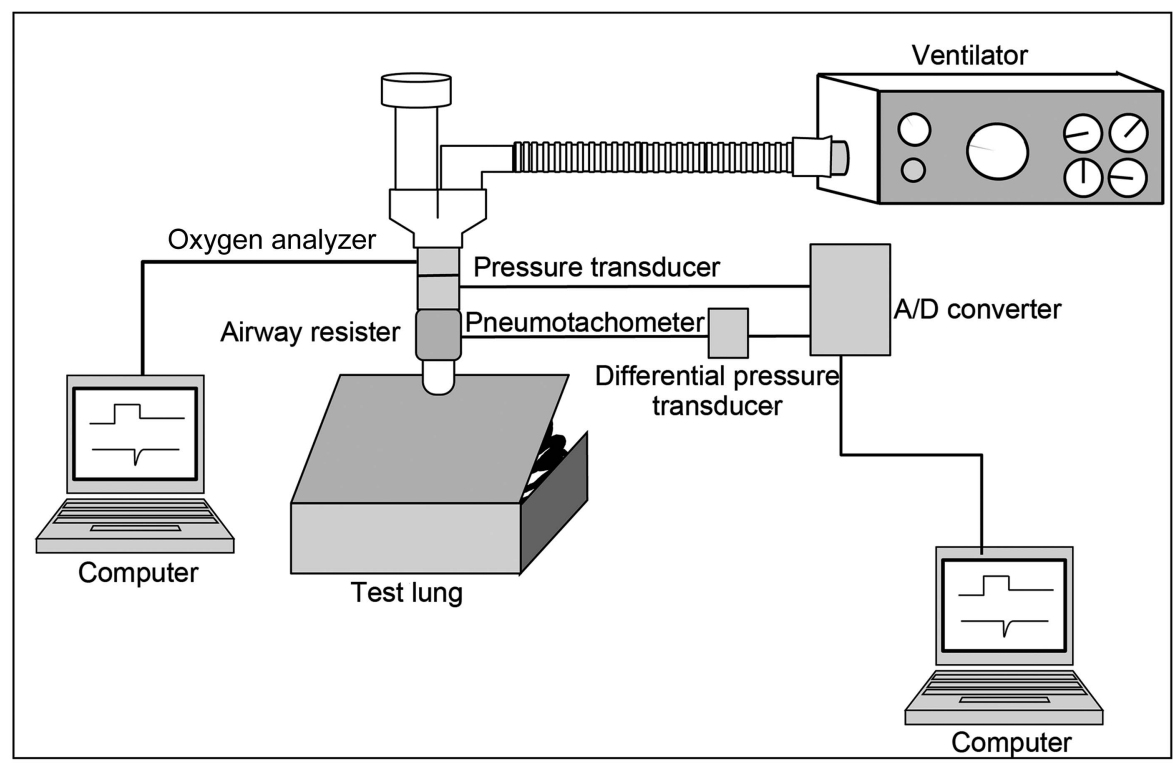

Fig. 1. Experimental setup. Each tested ventilator was connected to the TTL test lung via a ventilator circuit. An oxygen analyzer, a pressure transducer, a pneumotachometer connected to a differential pressure transducer, and an airway-resistance connector were placed between the Y-piece and the test lung. Oxygen concentration was collected directly by a computer; flow and airway-pressure signals were processed through an analog-to-digital (A/D) converter and saved on another computer.

ware (SPSS 11.01, SPSS, Chicago, Illinois). $P<.05$ was considered significant, but we discuss only differences that were both statistically significant and $>10 \%$.

\section{Results}

The difference in $\mathrm{V}_{\mathrm{T}}$ error was statistically significant among the ventilators. Figure 2 shows percent error of delivered $\mathrm{V}_{\mathrm{T}}$ for each ventilator. In general, $\mathrm{V}_{\mathrm{T}}$ error was greater at a $\mathrm{V}_{\mathrm{T}}$ of $300 \mathrm{~mL}$ than at 500 and $700 \mathrm{~mL}$. Delivered $\mathrm{V}_{\mathrm{T}}$ was less than set $\mathrm{V}_{\mathrm{T}}$ with the Pneupac VR1 and CAREvent MRI and greater with the iVent201 and ParaPAC 200DMRI. Error was negligible with the Servo-i. $\mathrm{V}_{\mathrm{T}}$ error was greater at $0.02 \mathrm{~L} / \mathrm{cm} \mathrm{H}_{2} \mathrm{O}$ than at 0.05 $\mathrm{L} / \mathrm{cm} \mathrm{H}_{2} \mathrm{O}$ with the Pneupac VR1 and CAREvent MRI and less with the ParaPAC 200DMRI and Servo-i $(P<.05)$.
Compliance had no effect on $\mathrm{V}_{\mathrm{T}}$ with the iVent201. $\mathrm{V}_{\mathrm{T}}$ error was greater at $20 \mathrm{~cm} \mathrm{H}_{2} \mathrm{O} / \mathrm{L} / \mathrm{s}$ than at $5 \mathrm{~cm} \mathrm{H}_{2} \mathrm{O} / \mathrm{L} / \mathrm{s}$ with the Pneupac VR1 and CAREvent MRI and less with the ParaPAC 200DMRI, iVent201, and Servo-i $(P<.05)$ (Fig. 3).

At an $\mathrm{F}_{\mathrm{IO}_{2}}$ of 1.0, the difference between set and actual values was small for all ventilators. At 0.6 (or air mix), $\mathrm{F}_{\mathrm{IO}_{2}}$ error was $25.3 \%$ with the CAREvent MRI (Fig. 4). At 5 and $10 \mathrm{~cm} \mathrm{H}_{2} \mathrm{O}$, PEEP error was $42.5 \%$ and $17.1 \%$ with the CAREvent MRI and $-29.2 \%$ and $-19.0 \%$ with the iVent201 (Fig. 5).

At a high-pressure alarm setting of $30 \mathrm{~cm} \mathrm{H}_{2} \mathrm{O}$, peak inspiratory pressure was $29 \pm 1.3 \mathrm{~cm} \mathrm{H}_{2} \mathrm{O}$, and at $40 \mathrm{~cm} \mathrm{H}_{2} \mathrm{O}$, it was $38.3 \pm 2.1 \mathrm{~cm} \mathrm{H}_{2} \mathrm{O}$ with all ventilators. The pressure-relief valves worked in each ventilator. 


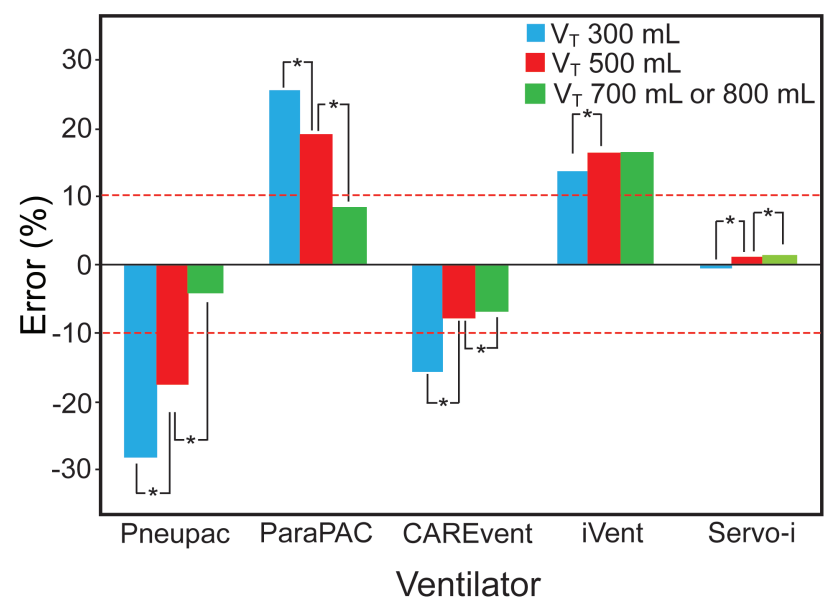

Fig. 2. Tidal volume $\left(\mathrm{V}_{\mathrm{T}}\right)$ error (\% difference between set and actual values) was determined for each ventilator at $V_{T}$ of 300,500 , and $700 \mathrm{~mL}$. $\mathrm{V}_{\mathrm{T}}$ error varied among the ventilators. As $\mathrm{V}_{\mathrm{T}}$ increased, $\mathrm{V}_{\mathrm{T}}$ error decreased in the Pneupac VR1, ParaPAC 200DMRI, and CAREvent MRI. For $\mathrm{V}_{\mathrm{T}}$ of $300 \mathrm{~mL}$, percent error was above $\pm 10 \%$ for the Pneupac VR1, ParaPAC 200DMRI, CAREvent MRI, and iVent201. For $V_{T}$ of $500 \mathrm{~mL}$, percent error was above $\pm 10 \%$ for the Pneupac VR1, ParaPAC 200DMRI, and iVent201. For $V_{T}$ of $700 \mathrm{~mL}$, percent error was above $\pm 10 \%$ for the iVent201. Red dashed lines indicate $10 \%$ error. ${ }^{*} P<.05$.

\section{Discussion}

In this study we tested MRI-compatible ventilators out of the MRI suite. We found that differences in $\mathrm{V}_{\mathrm{T}}, \mathrm{F}_{\mathrm{IO}_{2}}$,

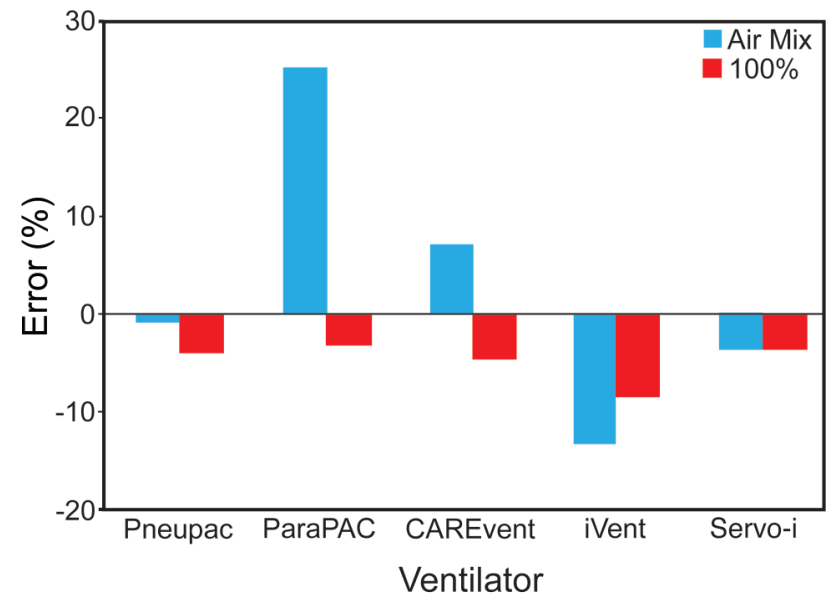

Fig. 4. $\mathrm{F}_{\mathrm{IO}_{2}}$ error (\% difference between set and actual values) for each ventilator. $\mathrm{F}_{\mathrm{IO}_{2}}$ error was small at 1.0. It increased at 0.6 and air-mix settings, especially with the ParaPAC 200DMRI.

and PEEP error were statistically significant among the ventilators. Percent $V_{T}$ error was greater at the low $V_{T}$ setting. PEEP and $\mathrm{F}_{\mathrm{IO}_{2}}$ deviated from the set values, and physicians should carefully observe the respiratory and hemodynamic status of patients during transport and MRI.

In standards laid down by the American Society for Testing and Materials, $\mathrm{V}_{\mathrm{T}}$ error within $\pm 10 \%$ of the set value is allowable: at $\mathrm{V}_{\mathrm{T}}=300$ and $500 \mathrm{~mL}$, the Pneupac VR1, ParaPAC 200DMRI, CAREvent MRI, and iVent201 exceeded this margin, and at $\mathrm{V}_{\mathrm{T}}=700 \mathrm{~mL}$, the iVent 201
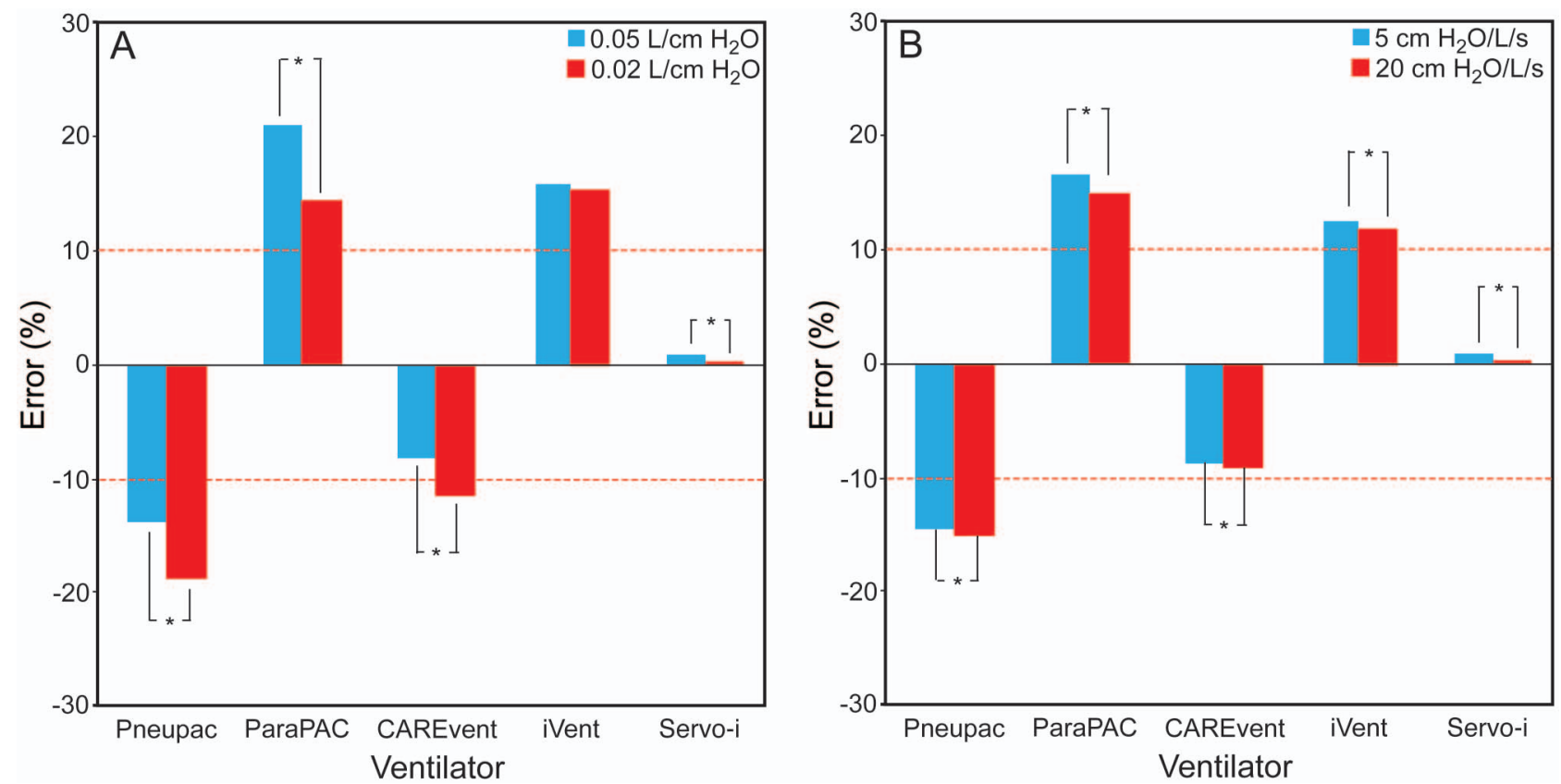

Fig. 3. Effect of compliance and resistance on tidal volume $\left(V_{T}\right)$. A: Effect of compliance. With the Pneupac VR1, ParaPAC 200DMRI, and CAREvent MRI, delivered $\mathrm{V}_{\mathrm{T}}$ was smaller at $0.02 \mathrm{~L} / \mathrm{cm} \mathrm{H}_{2} \mathrm{O}$ than at $0.05 \mathrm{~L} / \mathrm{cm} \mathrm{H}_{2} \mathrm{O}$. Greater error occurred with the Pneupac VR1 and CAREvent MRI than with the ParaPAC 200DMRI. B: Effect of resistance. With the ParaPAC 200DMRI, resistance influenced delivered $\mathrm{V}_{\mathrm{T}}$. Red dashed lines indicate $10 \%$ error. ${ }^{*} P<.05$. 


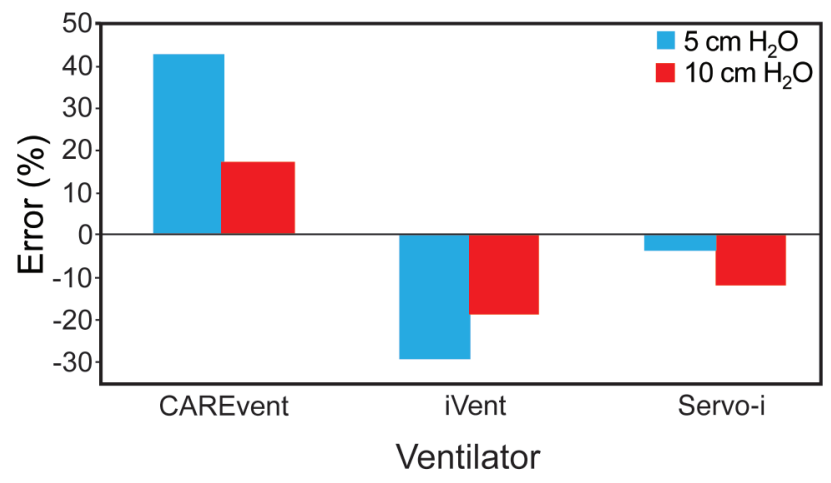

Fig. 5. PEEP error (\% difference between set and actual values) for each ventilator. PEEP exceeded the set level with the CAREvent MRI and fell short with the iVent201.

exceeded this margin. Except for the Servo-i, all tested ventilators were portable models. Previous studies ${ }^{4-8}$ evaluating the performance of portable ventilators found similarly high $\mathrm{V}_{\mathrm{T}}$ errors as in our study. Chipman et al ${ }^{5}$ evaluated the performance of 15 transport ventilators, which generally delivered less than set $\mathrm{V}_{\mathrm{T}}$ : in test instances, at $\mathrm{V}_{\mathrm{T}}$ of 500 and $1,000 \mathrm{~mL}$, error was $>10 \%$ in one third of the tests $(28 / 78)$, and at $\mathrm{V}_{\mathrm{T}}$ of $1,000 \mathrm{~mL}$, error was $>10 \%$ in half of the tests (32/78). In the present study, with the Pneupac VR1, ParaPAC 200DMRI, and CAREvent MRI, as set $\mathrm{V}_{\mathrm{T}}$ increased, $\mathrm{V}_{\mathrm{T}}$ error decreased. Flow is also dependent on oxygen supply pressure and lung resistance and compliance, and rather than measuring flow, portable ventilators simply control inspiratory valve opening to control flow (volume). Therefore, a difference between set and actual values is to be expected.

During volume control ventilation, some of the delivered gas volume is compressed in the ventilator circuit. To compensate for this, some ICU ventilators incorporate feedback by measuring the compliance of the circuit and pressure in the airway. Lacking this function, the Pneupac VR1, ParaPAC 200DMRI, and CAREvent MRI delivered lower $\mathrm{V}_{\mathrm{T}}$ at a compliance of $0.02 \mathrm{~L} / \mathrm{cm} \mathrm{H}_{2} \mathrm{O}$ compared with $0.05 \mathrm{~L} / \mathrm{cm} \mathrm{H}_{2} \mathrm{O}$. In volume control mode, higher airway pressure and greater compression volume at a compliance of $0.02 \mathrm{~L} / \mathrm{cm} \mathrm{H}_{2} \mathrm{O}$ resulted in lower $\mathrm{V}_{\mathrm{T}}$ compared with $0.05 \mathrm{~L} / \mathrm{cm} \mathrm{H}_{2} \mathrm{O}$. The Pneupac VR1 and CAREvent MRI delivered lower $\mathrm{V}_{\mathrm{T}}$ than set $\mathrm{V}_{\mathrm{T}}$. At low compliance, the difference between their set and actual values was greater than with the ParaPAC. We investigated only volume control mode, and resistance had a small effect on delivered $\mathrm{V}_{\mathrm{T}}$.

We measured $\mathrm{V}_{\mathrm{T}}$ with a pneumotachometer and differential pressure transducer using ambient temperature and pressure dry (ATPD). Actual $\mathrm{V}_{\mathrm{T}}$ should be measured at body temperature and pressure saturated with water vapor (BTPS). Heat-and-moisture exchangers trap water vapor in expiratory gas, so $\mathrm{V}_{\mathrm{T}}$ is underestimated; some ventila- tors correct $\mathrm{V}_{\mathrm{T}}$ to BTPS in screen displays. However, no ventilators evaluated in this study have this function. The Servo-i and iVent201 compensate compression volumes, but this did not influence our measurements. Therefore, we did not convert our ATPD values to BTPS values.

In air-mix mode, $\mathrm{F}_{\mathrm{IO}_{2}}$ was $25 \%$ higher than set $\mathrm{F}_{\mathrm{IO}_{2}}$ with the ParaPAC 200DMRI, and the difference from set $\mathrm{F}_{\mathrm{IO}_{2}}$ exceeded $\pm 10 \%$ with the iVent201. The Pneupac VR1, ParaPAC 200DMRI, and CAREvent MRI aspirate ambient air using the Venturi effect and do not measure $\mathrm{F}_{\mathrm{IO}_{2}}$. Entrained air volume depends on oxygen flow and crosssectional area, and oxygen flow is dependent on supply gas pressure and resistance. Consequently, $\mathrm{F}_{\mathrm{IO}_{2}}$ is not necessarily constant. These ventilators do not measure $\mathrm{F}_{\mathrm{IO}_{2}}$ and do not correct error. Blakeman and Branson ${ }^{6}$ reported that $\mathrm{F}_{\mathrm{IO}_{2}}$ exceeded $\pm 5 \%$ of preset $\mathrm{F}_{\mathrm{IO}_{2}}$ with portable ventilators. We found that PEEP error ranged from -29.2 to $42.5 \%$. Chipman et $\mathrm{al}^{5}$ also reported that several portable ventilators did not maintain PEEP at set values.

As a bench study, our protocols were not performed near operating MRI equipment: it is possible that a strong magnetic field may affect the performance of ventilators. Williams et $\mathrm{al}^{9}$ tested MRI-compatible ventilators near and away from MRI equipment, however, and reported that performance was similar. We also evaluated only one basic model of each ventilator relying on the manufacturers' quality-control procedures to ensure that all products had the same characteristics, we thus assumed that each was a typical example.

\section{Conclusions}

After bench-testing the performance of MRI-compatible ventilators, we found significant differences between set and actual values for $\mathrm{V}_{\mathrm{T}}, \mathrm{F}_{\mathrm{IO}_{2}}$, and PEEP. Due to the relatively poor performance of MRI-compatible ventilation equipment used during patient transfer to the MRI suite, we recommend monitoring respiratory and hemodynamic status in all ICU patients. Appropriate vigilance is also essential during ventilation while imaging.

\section{REFERENCES}

1. Menon DK, Peden CJ, Hall AS, Sargentoni J, Whitwam JG. Magnetic resonance for the anaesthetist. Part 1. Physical principles, applications, safety aspects. Anaesthesia 1992;47(3):240-255.

2. Peden CJ, Menon DK, Hall AS, Sargentoni J, Whitwam JG. Magnetic resonance for the anaesthetist. Part 2. Anaesthesia and monitoring in MR units. Anaesthesia 1992;47(6):508-517.

3. Zanetta G, Robert D, Guérin C. Evaluation of ventilators used during transport of ICU patients-a bench study. Intensive Care Med 2002; 28(4):443-451. 
4. Lyazidi A, Thille AW, Carteaux G, Galia F, Brochard L, Richard JC. Bench test evaluation of volume delivered by modern ICU ventilators during volume-controlled ventilation. Intensive Care Med 2010; 36(12):2074-2080.

5. Chipman DW, Caramez MP, Miyoshi E, Kratohvil JP, Kacmarek RM. Performance comparison of 15 transport ventilators. Respir Care 2007;52(6):740-751.

6. Blakeman TC, Branson RD. Evaluation of 4 new generation portable ventilators. Respir Care 2013;58(2):264-272.
7. Boussen S, Gainnier M, Michelet P. Evaluation of ventilators used during transport of critically ill patients: a bench study. Respir Care 2013;58(11):1911-1922.

8. Blakeman TC, Rodriquez D Jr, Hanseman D, Branson RD. Bench evaluation of 7 home-care ventilators. Respir Care 2011;56(11):17911798.

9. Williams EJ, Jones NS, Carpenter TA, Bunch CS, Menon DK. Testing of adult and paediatric ventilators for use in a magnetic resonance imaging unit. Anaesthesia 1999;54(10):969-974.

This article is approved for Continuing Respiratory Care Education credit. For information and to obtain your CRCE

(free to AARC members) visit www.rcjournal.com 